\title{
Transforming Environmental Psychology
}

\begin{abstract}
Although it is recognised that the individual and the external world are linked in complex and mutual ways and can only be treated together as one phenomenon there is little evidence that transactionalist approaches, despite potentially providing a truly distinctive approach for environmental psychology, have been fully understood or operationalised. We take as our starting point the theoretical proposition that individuals are the sum of their social relations, i.e., they are the cause and consequence of their relations to others and the environment. Therefore environmental psychology should give priority to examining the reciprocity between people and environment and the ways in which they mutually reproduce the material conditions for their existence. Drawing on the example of sustainable development, they argue that any attempt to develop a sustainable society has to understand how the relationships between individuals and their social contexts can be changed. Thus the emphasis in a transformative environmental psychology should shift to the relations of production and consumption and the social and political relations within which values, attitudes and behaviours are formed, and unsustainable ways of living and working as well as the environment are produced and reproduced.
\end{abstract}

Keywords: relations of production; relations of consumption; political relations; sustainable development; transformative

\section{Introduction: A short historical account of the themes and questions of environmental psychology}

The significance of Proshansky, Ittelson and Rivlin's landmark publication Environmental Psychology: Man and his Physical Setting (1970) cannot be overestimated as it brought together for the first time researchers from the physical sciences, design professions and social sciences to focus on the problematic nature of people-environment relations from an interdisciplinary position. It also sought to motivate research on diverse environmental settings in which generalizations could be made about the role of the environment on people's behaviour. Environmental psychologists, it was assumed especially by architects, held the magic key that would unlock insights into human behaviour such that user needs might be met more satisfactorily. Although the relationship between psychology and architecture may not have fulfilled its early promise because, it is argued, environmental psychologists could only provide general principles in response to the specific needs of practitioners (Uzzell, 2000a), the engagement at least served notice that psychology had a potential to make policy as well as practical contributions to the resolution of environmental 'problems'.

The involvement of psychologists and the genesis of environmental psychology also have to be seen against the backdrop of the rise of the environmental movement and increasing concerns about the impact of humans on the local as well as the global environment. Key publications like Silent Spring (Carson, 1962) and the Club of Rome's Limits to Growth (Meadows, Meadows et al, 1972) as well as the first major United Nations Conference on the Environment (1972) all highlighted the need for action. What differentiates the arguments put forward more than 30 years ago from those being voiced today is that at the time the logic and legitimacy of economic growth were questioned, while today the dominant notion is that economic growth and environmental needs should be harmonised. We believe that there is a 
need to reconsider this notion, while taking on board issues of environmental justice and the need of the countries of the Global South to grow in order to be able to satisfy the needs of their populations.

Despite the raison d'être of environmental psychology being the environment, it is paradoxical that what is meant by environment is rarely discussed. Critical contributions made in other areas of the social sciences have not been considered much (Castree and Braun, 1998, Lefèbvre 1991). In her review of the Handbook of Environmental Psychology (2002), Susan Saegert makes a similar point when she discusses what is missing in the Handbook: "Current theories of the nature of space as a social product and lived experience are also not included. For example, Bourdieu's, Lefebvre's, and de Certeau's contributions to our understanding of everyday life deal directly with the experience of space and are increasingly prominent in discussions of environment-behavior relations." (Saegert, 2004, p262). In environmental psychology there has been a tendency to classify research in terms of the natural or built environment, although recent research on sustainability and sustainable development (Bonnes and Bonaiuto, 2002; Gardner and Stern, 2002; Vlek and Steg, 2007) has in some respects brought these two worlds together. A nascent area of conservation psychology has been defined as "the scientific study of the reciprocal relationships between humans and the rest of nature, with a particular focus on how to encourage conservation of the natural world." (http://www.conservationpsychology.org/ site accessed 24 November 2007). This work focuses on how caring attitudes towards nature, biodiversity and wildlife can be inculcated into an essentially urban population, and as a consequence what techniques can be employed to change the public's behaviours, generalize what they learn in places such as zoos to the wider environment, and influence national environmental policies in a largely antipathetic political context. Aside from erroneously characterising environmental psychology as deterministic (Clayton and Brook, 2005), conservation psychology seems to hold a strongly ideological position with regards to nature, treating nature as external to society ("first nature") rather than seeing it as a phenomenon which is socially produced and constructed ("second nature") (Castree and Braun, 1998, Castree 2005).

In this paper we argue for a transformative environmental psychology. Transformative environmental psychology starts with a critical assessment of structures and processes in which people's relationship to their environment is shaped, and at the same time is formed by the action of people. It should challenge the usually taken-for-granted structures and processes (i.e., the status quo) and not just the values, perceptions, attitudes and behaviours that result from them. Again, this should not be problematic for environmental psychologists as, perhaps more than in any other area of psychology, they are sensitive to issues of context and the nature of much environmental psychology research is inter-disciplinary if not transdisciplinary (Lawrence and Després, 2004). A defining attribute of environmental psychology is that it is often applied and policy-oriented. This involves formulating strategies and practices with the goal of changing the behaviours of individuals and groups, instead of looking at the relationship between the political, economic, and social contexts and the actions of individuals. Psychologists have a repertoire of skills and techniques that are used to bring about change and these could be used to work with individuals and groups to understand the conditions in which change occurs and why it does not occur. The focus of much contemporary psychology in respect of sustainable development is to identify the drivers of consumption behaviour as if people live in a social, cultural and political vacuum. In this paper we advocate examining how people position themselves as social actors, how they make sense out of the world, and how they see opportunities and barriers to action and in so doing understand the conditions of social life which need to be changed. Transformative 
Psychology, as we will argue, would then have the task to support individuals and groups in creating conditions in which more sustainable lifestyles can be lived and a more sustainable society flourish.

\section{Environmental Psychology: the loss of context in theorising about behaviour change}

Environmental psychology has framed research in architectural, urban and natural environment settings around two contrasting perspectives. On the one hand, how can we adapt the environment to people's needs and what is the contribution of environmental psychology in this process? Alternatively, how can people adapt to the environment such that their impacts are reduced or redirected? Consequently, environmental psychology has long had an applied and policy-oriented emphasis, perhaps now more important than ever in terms of contributing to consumer behaviour change strategies for mitigating and adapting to the effects of climate change. With so much research in the early years focussing on understanding, meeting and changing user needs and preferences, it is not surprising that psychologists should be called upon to exercise their expertise in respect of understanding consumer attitudes and behaviours; consumers are, after all, a particular type of user category. If psychology is the 'science of human behaviour', then it ought to be well placed to draw upon the lessons of some eighty years of psychological research on understanding and changing people's perceptions of, attitudes to and behaviour in the environment. However, it might equally be argued that eighty years of research has perhaps not equipped psychology well for this task. Psychology - even social psychology - has largely developed individualistic and reductionist models of behaviour which have rarely positioned behaviour within its larger social, economic and political context.

Behaviour is not only the product of rational, deliberative and individual evaluation. It is also based on habit and cultural tradition, emotional impulses, the influence of family and friends and social norms as well as wider trends. Moreover, while values and attitudes are clearly important in influencing behaviour, values and attitudes are not formed in a social and cultural vacuum. They are embedded, nurtured and emerge from a social context, such as class, gender, ethnicity, and environmental settings, resulting in specific everyday cultures. To understand the levers of behaviour change at either an individual or collective level one must be sure that the explanatory or independent variables are relevant and decisive in terms of explaining behavioural processes. If driving a car is part of a class and gender-specific culture and if this culture is reinforced by public images of masculinity through advertisements, magazines, and the persistence of unequal gender relations (Steg, 2005), it is important to tackle the cultural as well as the societal structures that support such practices if one wants to achieve behaviour change in car usage. If supermarkets are increasingly built out of reach of public transport and their low prices lead to the demise of small shops in inner cities, then it makes no sense to only tackle a masculine car culture or to promote the value of nature and make people aware of the dangers cars represent to the natural environment. It is necessary to rethink and take measures to change shopping facilities and challenge a 'shopping culture' which is centred on edge city, car dependent superstores and shopping malls. Arguing that values and norms are the decisive reasons why people do or do not engage in sustainable behaviours implies that dependent variables are being treated as independent variables.

Although there is a growing interest by psychologists in more subtle techniques of social change and influence, such as the use of techniques employing social norms, social cohesion and social identity processes (Uzzell, Pol and Badenas, 2002; Pol, 2002; McKenzie-Mohr, 
2000; Bonaiuto, Breakwell, and Cano, 1996), the majority of psychological work on behaviour change has drawn upon simplistic linear models of information/attitude/behaviour. These suggest that raising awareness and providing people with information will change their attitudes which in turn will lead to a change in behaviour. If this were a truly effective strategy then people would not smoke, they would take exercise and not consume saturated fatty foods. Why should we assume that alerting people to environmental problems will be any more effective in changing their behaviours when arguably they have less at stake personally? Again, what we can conclude from eighty years of research in psychology is that pinning down the relationship between attitudes and behaviour is highly problematic attitudes are not a straightforward predictor of or precursor to behaviour. Indeed, attitudes may be a consequence of the self-monitoring of our own behaviour and the situations in which this behaviour occurs (Bem, 1972).

\section{The effect of a non-contextualised notion of behaviour on policies of behaviour change}

Given that there is now widespread agreement amongst climate scientists that global warming is on a catastrophic trajectory and that waiting for attitudes to change and new sustainable behaviours to be established is too uncertain and will take too long, governments are now exploring policies and measures to directly impact upon behaviour through mechanisms of compulsion and restricting choice. The rationale behind coercive behaviour-change strategies focussing on consumption is that as carbon emissions are a consequence of excessive consumption, the consumer is therefore regarded as responsible by pursuing ignorant, errant and self-serving and inappropriate consumption behaviour. Such strategies have received some reinforcement because there is evidence that they do work and are even popularly supported where they are seen to be in the public good. For example, the introduction of the compulsory wearing of seat belts in cars and crash helmets on motorcycles, and the banning of smoking on planes, trains, public buildings and most recently restaurants and pubs have been successful and have been approved by the majority of citizens. However, such policies can lead to resistance and resentment and as a consequence have unpredicted and unintended consequences. For example, over one hundred local authorities in the UK have introduced an Alternative Weekly Collection scheme of waste and recyclables. In an AWC scheme nonrecyclable and recyclable waste is collected in alternative weeks. However, residents are not allowed to over-fill their wheelie-bin so there are strict limits on the amount of nonrecyclable waste which they can dispose, thereby forcing them to reduce and recycle. These schemes can be highly effective; in one scheme in Waverley borough (Surrey, England) recycling rates in terms of tonnage increased from approximately $25 \%$ to approximately $40 \%$ in less than nine months. But this improvement came at a high political price. At the most recent local government election (May, 2007) the political party which introduced the scheme went from a 29 - 26 seat Council majority to losing 23 seats so that the opposition party now has 51 seats compared with the former controlling party which now has three. It was widely accepted that the introduction of the AWC scheme was one of two significant factors in this reversal. Clearly, this form of compulsion, if not seen to be in the public good was at least poorly explained to the public. This may say a great deal about how alienated the majority of the population feels about their 'ownership' and stake in the environment.

Coercion may be a hard bullet to bite in a political environment that for twenty years has advocated a creed of choice not legislation, freedom not a 'Nanny State'. In our view, one of the reasons why people show little concern for environmental degradation and are cynical and critical about the actions of governments, is that they feel a lack of control over and 
responsibility for the environment. Research has shown that people may accept responsibility for their immediate environment but they often see the immediate environment as not being a problem - it is more distant environments which are seen to be at risk or under threat and they are powerless to do anything about these (Uzzell, 2000b; Dunlap, Gallup \& Gallup, 1993). Thus, they might as well carry on with a 'business as usual' attitude; environmental problems are too large for them to do anything about or have an impact upon. Indeed, if one takes into account the scale on which corporations and other powerful agents pollute the environment, people are correct in seeing their contribution as almost negligible. ${ }^{1}$ Coercive measures and even strategies of persuasion may reinforce feelings of powerlessness and the conviction that the powerful agents and agencies will take care of things - or not. While coercive measures may be successful in bringing about specific behaviour changes, they do not change people's sense of alienation and powerlessness and thus tend to reinforce people's conviction that they are not responsible and cannot do anything about their living conditions and much less about broader environmental hazards. The changes achieved through coercive measures may not necessarily generalise to other behaviours and so the gain is short-lived and limited in scope. The more individuals are deprived of control over their living conditions, the more they are likely to look for satisfaction through consumerism and through identity construction via carbon generating consumption of goods (e.g., cars) and services (e.g., overseas holidays). It is not feasible to devise a coercive strategy for each single behaviour change, and given what we have written above about cultural context, it is probably not possible anyway.

\section{Contextualising behaviour - putting production into environmental psychology}

Trying to understand behaviour, social norms and values in their gender, ethnic, class, place and other specific cultural contexts as well as within their broader consumerist societal context, suggests we transcend the boundaries of consumption and examine the ways in which consumption processes are created and shaped by production processes. Will focussing primarily on consumer action deliver the low carbon society aspired to by governments given the tacit conspiracy between the desires of the hedonistic consumer to consume and the carbon-intensive producer to sell as much as possible? From this perspective, attacking consumer behaviour simply addresses the 'downstream' symptoms rather than the 'upstream' causes of environmental problems.

In reviewing the application and impact of environmental psychology, Gärling and Hartig (2000) suggest that environmental psychology research should examine the sustainability of production processes:

"Environmental psychology may become more and more concerned about helping societies to develop sustainable environments. The application of this research ranges from one extreme, focusing on changes in the quality and quantity of demand (the need to change people's lifestyles), to another extreme, focusing on changes in the production process to make it more sustainable. The latter may however never be possible unless people change their aspiration levels, pay more attention to equity issues, and so forth. We see a new need for environmental psychology research that illuminates the consequences for people of new production processes, e.g., the production of sustainable housing. We believe that this means

\footnotetext{
${ }^{1}$ As Plant and Plant (1991) point out, if $100 \%$ of all private households in the US would recycle $100 \%$ of their solid waste, this would add up to $1 \%$ of all the solid waste that is produced.
} 
that environmental economists, engineers, and applied natural scientists will be among the new "practitioners" to a considerably greater extent than was the case in the past." (Gärling and Hartig, 2000, p.31)

What is particularly significant about this 'agenda' for environmental psychology is that Gärling and Hartig (ibid) highlight the importance of examining production. There has been very little research activity or even discussion in environmental psychology about the role of production in changing societal consumption. Refocusing our attention on production and its relation to consumption is important not only for transforming our unsustainable society but also for transforming environmental psychology.

Notwithstanding Gärling and Hartig's (ibid) important suggestion, their analysis retains its focus on the consumer. Their call for people to change their aspiration levels as a means of influencing production is still essentially consumerist in orientation. It does not explain, for example, where aspirations come from. It assumes production is a neutral process which exists in a benign state and is simply responsive to demand; that it is consumer demand that drives production and that the producer is only doing his/her job by meeting that demand. But as we know, this is a myth; it is predominantly producers who create and drive demand. Aspirations are not 'naturally' formed but are created, developed and reinforced in specific ways through a form of production that needs to realise its products through the market and thus has to create a market demand for its products. For example, everybody needs to eat and drink, but that this need appears in the form of a desire for burgers and sugar saturated fizzy drinks is the result of companies promoting these desires. Likewise, everybody needs to get from one place to another in their daily life. But the fact that this need materialises in the need to travel by car is the result of urban space produced through state planning and powerful private interests that makes driving cars the policy option of choice in terms of short term financial and medium term electoral preferences, as well as being socially, culturally and economically desirable if not necessary.

Another factor that may have led to prioritising consumption and individual consumer behaviour as opposed to production and the forms of production, may have been the renewed belief in theories of the power and benign effects of free markets. If we assume that producers compete freely among each other and therefore consumers are the ones who steer production through their demands, it seems logical to try to change consumer behaviour in order to achieve a change in production. The agenda suggested by Gärling and Hartig (2000) is informed by an assumption of a power balance between producers and consumers, where the latter are decisive in influencing the actions of the former. This assumption is questionable. Consumers are rarely organised and able to assert collective pressure - they can only operate through individual and largely ineffectual action. It is only when consumers become organised such as the fuel protests in Britain in 2000 (BBC, 2000) that they can challenge producers. In such cases it is conscious political action that may bring about changes, not the anonymous, free market forces that supposedly produce the common good through the sum of individual actions. While a consumer-oriented strategy can rely on the limited power that consumers may exercise through not buying certain goods, it ignores the fact that greater power and better organised forces are working in the opposite direction, namely to sell as much as possible at any, including environmental, cost. This is well illustrated by an interview with Dorothy Thompson, the CEO of Drax power station, the largest coal-fired power station in the UK providing 7\% of Britain's electricity, but also Western Europe's largest industrial source of carbon dioxide. In an interview on whether decisions should be based on economics or environmental ethics, Thompson argued, "If 
you're faced with two decisions, and one's going to make you a lot of money but give no environmental benefit, and one's going to make the same amount of money but result in an environmental benefit, it's very clear which one you go for." However, when subsequently asked whether the company would take the pro-environmental option if it compromised profitability, Thompson replied "No, because my shareholders wouldn't support it. They invest in us for a profit. We're not a not-for-profit organisation.” (Harris, 2007, 31).

The environmental movement in the seventies demanded a fundamental transformation of production and consumption, and challenged the notion of growth as the basis of the Western way of life. We can only offer some hypotheses as to why, as we see it, a shift in the emphasis on policies towards consumption rather than production has occurred. One hypothesis is that the strong resistance of capital (i.e., shareholders) to any substantial changes to the scope and forms of production, made the shift to changing consumer behaviour an easier option for bringing about change. Governments have more power over individual citizens than over large multinational corporations; consumers are a weak target and rarely have the resources and organisational capacity to resist. Moreover, as the task of consumers is to consume, so it seems 'natural' and plausible for governments to action the sustainable consumption narrative by requiring the public to reduce their consumption and for the public to receive this message as reluctantly understandable and inevitable.

The replacement of the notion of "ecodevelopment", which took as its starting point and goal of development the ecological balance, rather than profit or growth, by the notion of "sustainable development" has probably facilitated the shift from targeting producers to targeting consumers. The way in which the term "sustainable development" entered official documents sheds light on the way in which it has become a compromise between social actors/movements concerned with the environment, governments, and transnational corporations. Alain Lipietz, economist and leading member of the French Green Party recounts the story:

"The original idea of ecodevelopment began from the observation that the development model of the seventies entailed too much consumption of raw materials and produced too much waste. The first major United Nations Conference on the Environment, in Stockholm in 1972, endorsed an ecodevelopment model in which local communities were supposed to guard against these two errors. (...) Then came the second major conference, in Rio in 1992(...). One of the preparatory meetings was the United Nations Commission for the Environment, presided by Mrs. Brundtland, the social-democratic prime minister of Norway. The Commission immediately ran up against the opposition of the United States, which refused any discussion of ecodevelopment. It was permitted to say that the needs of the present generation should be satisfied without compromising the possibilities of successive generations, and to call this demand "sustainability." But the term "ecodevelopment" was taboo, to the extent that it connoted the end of unbridled free trade, the prohibition of the exploitation of one territory by another, and so forth."

(http://www.uwex.edu/ces/ag/sus/html/sustainable_development.html Site Accessed 1 May 2007)

It is very easy to be taken in by the seemingly positive language of sustainability. Sustainability is as likely to be used in discussions about company 'downsizing' and justifying redundancies as reducing carbon emissions. Sustainable as a signifier is comforting, constructive, and to be valued; it affirms the necessity in a positive and userfriendly way. Sustainability has become the new 'community', an idea that is inherently good 
and incontestable. However, sustainable development can mean almost anything. As Lélé expressed it:

'Sustainable development is a "metafix" that will unite everybody from the profit-minded industrialist and risk minimizing subsistence farmer to the equity-seeking social worker, the pollution concerned or wildlife-loving First Worlder, the growth-maximizing policy maker, the goal-oriented bureaucrat, and therefore, the vote-counting politician.' (Lélé, 1991: 613).

From the point of view of organising consensus and creating social cohesion, the confusing notions of sustainability can be seen as a strength rather than a weakness. To be effective, a term needs to be as broad as possible in order to enable different groups with even antagonistic interests to find their interests represented. For example, sustainability can mean producing the same quantity of goods (i.e. the same high levels of consumption) but in supposedly more environmentally 'friendly' ways. It can mean continuing to produce goods and services but ask or demand that people pay extra to offset carbon emissions.

\section{Strong and weak sustainability ... From consumption to the relations of production and consumption}

If we are to devise policies and actions that lead to more sustainable societies, we need to have a more sophisticated theoretical understanding of the role of consumption and production for sustainable development and its implications for sustainable ways of life.

Dobson (1996) differentiated between weak and strong sustainability with the question: what is to be sustained? In this context substitutability provides the legitimation for the nature of the answer. At one end of the continuum we would find that everything that exists in nature could be substituted by human-made products; if that were the case, nothing would have to be sustained. On the other hand, ideally, we would find the position that nothing can be substituted, therefore everything would have to be sustained (Table 1). The first argument is based on a view which sees nature in terms of its function or usefulness for humans. The second argument is based on a view that regards nature as a value in itself, independent of its utility for humans.

$* * * * * *$ Table 1 Here $* * * * * * *$

Huckle and Sterling (1999) return to differentiating between weak and strong sustainability around the question: how is sustainability to be achieved. For them weak sustainability implies retaining the status quo of societal relations which have been responsible for environmental degradation. Weak sustainability does not question the forms in which production is controlled; it claims that market forces can bring about a sustainable society. According to Huckle and Sterling, weak sustainability would mean substituting dangerous products for less dangerous ones, and the extensive for an intensive exploitation of nature. The growth in Corporate Social Responsibility (CSR), they claim, is a response aimed at reconciling corporate interests with environmental needs and the demands of concerned citizens and the environmental movement. Maintaining the current relations of production implies that there are few constraints on what and how corporations produce within a free market economy. For individuals, engaging in sustainable practices is expected to happen at the level of consumption only. The consumer is not expected to question the freedom of companies to produce what and how they want. As we have argued above, asking individuals 
to participate in sustainable development by wisely consuming what has already been produced is to put the cart before the horse.

Working within a model of weak sustainability assumes that there is a fundamental distinction between individuals and society. This is likely to place an emphasis on working on and persuading individuals to adapt to a given form of society which in itself is never defined, let alone questioned in any depth. Such an approach simply reproduces and reinforces the problems it is supposedly addressing, namely people's relative weakness and susceptibility in the face of demands and persuasions to consume more and more environmentally damaging products.

Strong sustainability contests such strategies and challenges the current relations of production by questioning the freedom of corporations and the workings of the free market and arguing for government and citizen intervention. This aims to not only change the character of products and the ways of production (i.e., CSR and government programmes like the UK Government's Market Transformation Programme), but also to question the need for, and thus the existence of, certain products and the scale of production in general. Furthermore, strong sustainability demands forms of participation that involve citizens in defining the political processes of societal control, as opposed to them just participating within a pre-determined framework.

\section{A model for strong sustainability}

We believe that environmental psychology can make a significant contribution to the development of more sustainable societies. This will be achieved, however, not only through a shift from focusing predominantly on consumption to including production, but also by employing a theoretical framework informed by an analysis of the relations of production and consumption and of the political relations within which natural resources are consumed and goods are produced and consumed in a way that leads to unsustainable societies.

Furthermore, any separation of consumption and production as if these are two independent processes, is ill-conceived. We put forward a preliminary model of strong sustainability that seeks to address some of the problems of weak sustainability identified above. The concepts presented in the following are theoretical frameworks that we think can engender new research questions. The concepts we suggest along with the questions they generate are broad enough to be used in different research settings according to the particular interests of the researcher.

\section{Relations of production}

There is a tendency to talk about 'the economy' as if it is a neutral entity, existing independently of human actors and being universally the same in all societies; indeed, one of the three pillars of sustainability is 'the economy'. We prefer the term 'relations of production'. It includes, but also goes beyond, questions as to whether we need or want economic growth. It asks whether and how the social relations within which goods are produced are sustainable or not. Thus, the question of 'the social' is not relegated to a specific domain existing outside the realm of the economy and the environment, but defines the economic, political and environmental sphere in a certain historical moment in a given place. The term relations of production prompts us to look at the social actors that are engaged in producing tools, housing, consumer goods, services, etc. and asks what their interests are, what the conditions of their actions are, what motivates them to act, with whom they co- 
operate, what the power relations between these actors are, how the conditions of production are organised and how this impacts on those who carry out the production process on each hierarchical level from the management to the worker on the shop floor or in the office.

Questions that define sustainable relations of production as democratic relations, in which all those implied in the process have a say, would include: who decides what, how much is produced and how? Who decides whether certain products are needed? To what degree are the workforce and the people living within the radius of the production process affected by that process included in the decision making concerning production? How does the production process affect their living and working conditions, their safety, health, and quality of life? The sustainability of the production process, that is the way in which it affects the natural and built environments, could be analysed by asking: what raw materials are used and what are the effects of the production process on the environment? What kinds of goods are produced and could the same needs be satisfied by goods with less damaging effects on the environment and on people's health? Of course, this also poses the question who should have the responsibility and legitimacy to pose such questions: governments, environmental pressure groups, schools, trade unions, NGOs?

\section{Relations of consumption}

Consumption is the hot topic in sustainable development. The term relations of consumption indicates that there is a relation between the way in which a society produces and the way in which it consumes. The concept also includes the power relations within the sphere of consumption, for instance between retailers and producers and between retailers and consumers. Bourdieu (1984) has analysed how consumption processes are part of the reproduction of class relations. For example, women, young people, and older people are often targeted in specific ways to increase their consumption. Norms of beauty, body fitness, and coolness are invented and applied to make sure that particular social groups consume as much as possible, in order to become what is mythologised to be a successful individual. Finally, relations of consumption are also about decisions concerning the ways in which consumer goods reach, or do not reach, the consumer. Issues in a research agenda looking at consumption would include the ways in which cities are built, transport and shopping facilities are provided, the images and cultures within which consuming goods are embedded, but also the ways in which consumption practices are part of other social practices like work, family life and leisure.

\section{$\underline{\text { Political relations }}$}

If we want to work towards a sustainable society we need to include political institutions and the ways in which they function into the programme of transformation. In this respect, the concept of 'social sustainability' is self-contradictory. If we aspire to build a sustainable society we have to transform social relations, instead of making the existing ones sustainable. For example, the notion of 'participation' is usually used to denote inclusion into an agenda that has not in the past been open to wider involvement and questioning by those who are to be included. Thus, challenging the political system and demanding true participation should also be central to a transformative environmental psychology that encourages and supports user involvement in the planning, design, management and use of the built and natural environment.

The model we are beginning to outline suggests a shift in the focus from individuals to the social relations within which unsustainable ways of living are produced and reproduced. It 
allows us to pose different questions and look at the issues we are interested in (how do (un)sustainable ways of life develop and what could sustainable ways of life look like?) in a more comprehensive way. For environmental psychology, this requires a theoretical approach that takes its point of departure from the idea that individuals are the sum of their social relations, i.e., they are the cause and consequence of their relations to others and the environment. Therefore, any attempt to develop a sustainable society and sustainable production cannot be brought about by regarding individuals as somehow independent of their social relations or by trying to change their behaviour regardless of the social and economic context in which they live. Rather, one has to understand how the relationship between individuals and their social contexts can be changed so that individuals have more control over their living conditions. The prominent notion of the commons dilemma in environmental psychology, derived from Hardin's of the "tragedy of the commons" (Hardin, 1968) is one that constructs a binary opposition between the individual and society and is thus not very helpful in understanding the ways in which individuals create society and are created by it. The perspective of a sustainable society leads ultimately to issues of empowerment, self-determination and democracy, not only in the political domain but also in the spheres of production and consumption.

This perspective does not have to start from scratch. The image of people with no other interest than consuming as much as possible, or of poor people who cannot afford to think of anything else than to make ends meet is too simplistic. There are many examples of social groups, which are seeking to change forms of production and consumption, such as consumer groups which try to encourage consumers to change purchasing habits and producers to make their products more sustainable; trades unions, and other workers' organisations, which promote the creation of 'green jobs' (cf. SustainLabour www.sustainlabour.org (accessed 22 November 2008); and Gereluk and Royer, 2001). We suggested at the outset that there should be a focus on understanding better how those who are changing not only behaviours but the conditions of behaviours are doing this and to learn from this. An interesting programme of research for psychologists, for instance, would be to focus on what leads people to join such movements.

In responding further to Gärling and Hartig's paper (2000), we would like to suggest that environmental psychology has a potentially more significant role than simply 'illuminating' the consequences of the development of environmentally friendly products, i.e., to engage in some form of environmental education. What can be gained from illuminating the consequences of environmentally friendly production if people cannot exercise any influence on production processes? Equally, simply illuminating the consequences of currently unsustainable production practices without suggesting how people can influence or control those processes, would only serve to alienate them further from their surroundings and reinforce feelings of powerlessness. Instead, we need to illuminate the potential opportunities for people's involvement in production processes in general (including the affordances and constraints of political engagement), and their potential impact upon sustainable practices in the future.

Apart from separating individuals, the environment and society, there is a tendency in the social sciences to pigeonhole social categories such that individuals are seen to fall into discrete groupings, even though an individual can and unavoidably must hold simultaneously several, even potentially contradictory, positions in society which can lead to conflicts when it comes to action. Graumann (1983) argues that we hold multiple identities which give us access to different aspects of society, different spaces and different realities. Turner, Hogg et al too, in social categorization theory (1987), highlight how social identity comes from 
categorical identification of the self with the more salient social categories of the group, and how such identification serves to stress the perception of similarities in the in-group and differences from out-groups. In some cases this may lead to an awareness of several selves. This is illustrated in the interview with the CEO of the Drax Power Station. When asked about her view of global warming, Thompson replied, "I find it quite a difficult subject. On a personal level, I believe there is a very, very high risk that climate change is real. And I think we, as a country, need to find ways of addressing it. Through Drax, I think my role is to provide as constructive a solution as I can. But I think that's got to be in recognition that ... you know ... I'm owned by shareholders, who are looking for value out of the business." (Harris, 2007, 30).

Thompson presents herself here as acting and thinking on three levels: her personal self, her self as citizen and her self as manager of a polluting company. Several things are striking in the way she articulates these three subject positions: what she is supposed to think as CEO is not without influence on what she calls the "personal level", because even there she will not say (at least not in public) that climate change is real, but only that there is a high risk it might be. She constructs herself as an active member of a larger collective by articulating the need of "we as a country" to address climate change, with which she implies that it is real, contrary to her reservations on a "personal level". As a manager though, she goes as far as to present herself as being deprived of her humanity as a free individual, since she is "owned" by shareholders. Nevertheless, her actions somehow mediate between all these three levels of her self by providing a 'constructive' solution. Understanding such multiple identities would be a pre-condition to illuminate the possibilities for workers and consumers, and even for managers to play a part in developing sustainable production processes.

\section{Discussion: Transforming Environmental Psychology}

We believe that it is time that the reductionist conceptual frameworks and methodologies that characterise much psychological research, including environmental psychology, come under greater scrutiny and are challenged not only in research on sustainability, but also in policy and practical arenas. Until now, it has been common practice within environmental psychology to conceptualise people as being part of more or less voluntarily-formed social groups. We are arguing that such a perspective ignores the overwhelming structural power relations that characterise contemporary societies. Class, gender, ethnicity, sexuality and age and space/place are the positions most often referred to in social science. As we appreciate that people may have multiple and simultaneously held identities, people also occupy more than one of these positions. Although it inevitably increases the complexity of research to take these different positions into account, if we are concerned to ensure that environmental psychology has an ecological validity - a characteristic unfortunately lacking in some other areas of psychology - then this is a price that has to be paid, but a worthwhile price if the results of our research will be more meaningful and applicable.

The remainder of this paper concludes with a discussion of the implications of this kind of approach for a transformative environmental psychology. We illustrate this by an extended discussion of how a focus on the relations of production and consumption from an environmental psychology perspective would contribute to a reformulated research agenda for environmental psychology in respect of sustainable development. 
From the influence of and the adaptability to the built and natural environment to the social production of the environment

Those undertaking environmental psychology research in the workplace may feel mystified why we are suggesting that 'production' should be put on the research agenda since there is already a psychology of work, looking at issues of control, worker satisfaction, environmental impacts, etc (cf. McCoy, 2002; McCoy and Evans, 2005; Becker and Steele, 1995; Sundstrom, 1986). It is noteworthy that most of the research in relation to work is undertaken in offices. This has been justified on the grounds that "more than $50 \%$ of working people in the United States work in offices" (McCoy, 2004, 443). Leaving aside the fact that in most countries in the world the majority of the workforce does not work in offices ${ }^{2}$, it is interesting that it is not deemed even necessary to make anything other than a numerical justification. For example, given that working conditions generally in offices are considerably better than those within a factory or on a farm, one might have thought that a justification based on need (i.e. working conditions) or contribution to the economy would be equally if not more valid. McCoy goes on to identify the impact on office design and management as a consequence of new technologies and economies, "Responding to new technologies, economies, and markets, organizations are seeking more fluid ways of supporting constantly changing functional requirements of people working within the organization." (ibid, p. 444). This description reads as if decisions made about people and their working environments are mechanistic, value-free and uncontested.

But what is so striking about office design, employee satisfaction and task performance is that the intended response of the employee is largely silence and compliance. The employee is there simply to respond in appropriate and pro-organisational ways to changed environmental contingencies. Notwithstanding the rise of worker participation in the 1960s and '70s, we have found little evidence that workers are able or expected to be involved in discussions and decisions about their work environment, let alone about production processes. The question of the democratisation of working practices and production is rarely addressed, nor the way in which working constitutes identities, i.e., impacts on the ways in which people see themselves, their relation to their immediate and broader environment and on the ways in which they act outside work. We suggest, therefore, that one task of environmental psychology would be to look at the ways in which the social production of the environment by corporations and workers/employees, that is, working processes and production decisions, impact upon the ways in which individuals experience the environment. The ultimate aim of such research would be to illuminate ways in which a democratisation not only of the sphere of the political, but also of the sphere of production and consumption could contribute to a more sustainable society.

The distinction between the sphere of production in which individuals are assumed to merely function, and the sphere of consumption which dominates individuals' leisure and domestic life and in which they form their identities and develop their values and norms, is relevant not only to environmental psychology but to the social sciences in general. Furthermore, it has been legitimated by a number of influential theories on the characteristics of postmodern or late modern societies, developed for instance by sociologists like Bauman (1992) and

\footnotetext{
${ }^{2}$ According to Pietro Basso (2003) there were 500 million people working in manufacturing in 1995, which is about three and a half times more then in 1950, while in the same period the world's populations has doubled. He claims that while the number of manufacturing workers has dropped in the West due to higher productivity, it has increased in the rest of the world. Around $80 \%$ of industrial workers, he claims, are now working outside Western countries.
} 
Maffesoli (1996) who claim that groups - Maffesoli talks about "tribes" - form, dissolve and form again quickly around different markers or symbols, for instance consumption patterns, neo-religious affiliations, etc.. Bauman (1992) writes:

"... in present day society, consumer conduct (consumer freedom geared to the consumer market) moves steadily into the position of, simultaneously, the cognitive and moral focus of life, the integrative bond of the society, and the focus of systemic management. In other words, it moves into the selfsame position which in the past-during the 'modern' phase of capitalist society - was occupied by work in the form of wage labour. This means that in our time individuals are engaged (morally by society, functionally by the social system) first and foremost as consumers rather than producers." (1992: 49)

One of the reasons why work has lost its integrating power, Bauman and others argue, is that people change their employment more often; they do not have life-long occupations engendering the strong identification, loyalty and pride in their craft that comes with time and stability. Other researchers, especially feminists, have argued that the notion of a stable lifelong employment was only ever true for a small section of the so-called core working class: male, highly qualified and native-born (McDowell, 1997). The overwhelming majority of manual workers have always been forced to be more flexible and less attached to their specific craft. However, we think that there is still a strong argument for taking people's working lives into account if we are interested in bringing about a more sustainable society.

While it seems true that at a systemic level, as Bauman argues, the integration of individuals into society functions through consumption (and the concentration of government policies on individuals as consumers can be seen to provide strong support for this theory), this does not necessarily imply that work has become insignificant in the everyday lives of individuals. The majority of the population in Western societies between 18 and 65 is employed. This means that most people spend most of their lifetime at work. It would thus seem unwise to exclude this dimension of everyday life from an analysis of behaviour, identity, place identity, or attitudes. It seems unlikely that this aspect of their life should play no role in forming people's identities. However, the significance of this impact in relation to other practices like leisure, consumption, domestic life, political or religious practices is an empirical question.

Through work, individuals not only produce and change themselves, they also transform existing environments and through this produce new environments. (This also occurs, of course, through consumption but this has received no shortage of research attention). More specifically, the ways in which people work, that is, social relations at work, the content of work, the materials with which people work, the aims of their work are a critical, source/origin of what is usually conceptualised as lifestyles, cultures, behaviour, values, and attitudes.

What we are suggesting here is a finely tuned investigation of concrete work processes and the ways in which they constitute gendered, ethnicised, aged, spatial identities. Or to express it more empathetically with the language of environmental psychology, we suggest that the relationship between people's work, their sustainable or unsustainable lifestyles, and the environment should gain more importance in environmental psychology research.

The salience and significance of this approach is appreciated when one poses these questions in respect of people engaged in production processes that are seen as damaging for the 
environment, such as energy or chemical production, and vehicle manufacturing. We provide some examples of the kind of research questions which could be of importance:

- How do we understand the relationship between work and people's values and lifestyles and what conceptual models of sustainability can be derived from these understandings?

- What kinds of work cultures are created in different work processes in different employment sectors and how do they influence the ways in which people live their domestic lives and consume in terms of sustainability?

- What kinds of identities are created in different work processes and how do they influence the environmental impact of work and leisure practices? How are these identities differentiated according to gender, ethnicity, age, sexuality, space and position in the hierarchy of the respective work place?

- How can social-psychological understandings of the formation of identities at work be used to devise effective policies for the democratisation of the production process?

- What is the significance of work identities (for instance producers' pride) for supporting or hindering the transition to a sustainable society?

- How do employees in different positions within a company negotiate possible value conflicts' between their task as producers (for instance of energy, chemicals, cars, etc.), their knowledge of the environmental impact of the production process, and their consumption choices?

- How do employees engaged in the production of environmentally damaging goods or services negotiate their interests as producers, consumers of such goods, and as inhabitants of a healthy planet?

The kinds of methods employed to investigate these questions are not necessarily different from those employed by environmental psychologists at present, such as interviews, surveys, focus groups and sorting tasks. But what these questions demand of a methodology is that they address the relationships between the groups under investigation and perhaps as a consequence examine those relationships in a more holistic way such that one tries to capture the life spaces in which people live, so that one can understand better their positions, identities and subsequent actions. Such an approach has both a spatial and temporal dimension. In spatial terms it would involve seeing people not simply as workers, or shoppers or recreationalists, but people in their work, domestic and leisure settings - each one of these settings will have some kind of influence on the other settings in which they operate. This might simply be collecting visual evidence such as stones and rocks collected on hikes and placed on their desk in their office as material for mental escape when the day goes badly, to investigating the kind of car they have that enables them to travel to work from home in such a way that it has priority over public transport. Equally, our perceptions, attitudes and actions are not formulated in an instance but have a history. Capturing that history, that is the time dimension of peoples' lives through their life histories is another way of understanding where they are now.

\section{From the investigation of lifestyles to the investigation of the origins of lifestyles}

There is another way in which environmental psychology could focus on production, this time on the practices of companies rather than on those whom they employ to execute the necessary work. While lifestyles or cultures can be studied in the sphere of consumption and domestic practices, their origins lie partly in the sphere of production, or better, the specific relations of production that characterise our contemporary societies. The need to make a 
profit from investment in the production of goods by selling them in the market engenders an industry of marketing strategies which in turn fuels the consumer society.

The majority if not all of these strategies are meant to create social identities connected to the consumption of specific goods. This process can be understood as tapping general human needs to transform them into specific needs that can only be satisfied by specific consumer goods. Sociologists, who suggest a shift from identification through production to identification in the market (as referred to above) as a characteristic of postmodern or late modern societies, put a great deal of effort in understanding these new forms of identification, but they often neglect the enormous influence of corporations - mediated through the marketing strategies of the advertisement industry - in producing, not only their products, but also the identities and therefore the lifestyles that should come with them. In short, one can argue that if one wants to understand lifestyles and consumption patterns, one needs to not only understand how they work once they are in place, but also the forces and practices by which they are put into place. This is an area where environmental psychologists can collaborate with researchers in cultural studies, who have produced analyses of identification processes through the appropriation and usage of consumer goods. (see for instance the journal Consumption Markets and Culture). However, as far as we know, these analyses have not been put into the context of sustainability issues.

The difficulties we face in moving towards a transformative environmental psychology could not be better illustrated than by quoting one of our referees whose response to this previous paragraph was:

"Ok, so what? Of course they fuel the economy. What would happen if everybody simply stopped consuming? The economy would go into recession or depression, and people would be worse off. My main point is that the authors really need to think about the complexity of the problem they are trying to solve here. People need to make a living; like it or not, consumption drives our economy (and well being); and the people in power are going to be reluctant to move away from the status quo that gives them wealth and power. In the end, it seems, it is going to come back around to motivating enough individual decision makers to change the political process to enact greener policies."

If we examine these arguments in detail we see that it is indeed this writer who has not thought about the complexity of the problems discussed. For example, we are not arguing that there should be no consumption, but we are questioning the way people are encouraged to consume more in ways that are wasteful of resources and products which would not be wanted if their desirability was not promoted. As Kasser (2002) has shown, higher consumption levels do not lead to a greater sense of well-being, quite the contrary (e.g., health-issues, life satisfaction). Consumption does drive our economy, but at what cost? The high consumption levels enjoyed in the global North destroys the agricultures of the global South (crops gown for feeding Northern cars rather than people; genetic modification and patenting of seed supplies, etc.), leads to environmental degradation and the abuse of workers' rights. Furthermore, we would agree with our referee that there is little prospect for change at the higher levels of societies because "the people in power are going to be reluctant to move away from the status quo that gives them wealth and power." It is for this reason we are suggesting that more democratic processes are required, which enable workers/consumers to engage in processes of change instead of being merely subjected to them. 


\section{Conclusion}

We summarise our principal conclusions as follows. Behaviours need to be analysed in their specific social and environmental contexts and within the larger context of the consumer societies in which we live. Environmental psychology has typically focussed on the users or consumers of those societies and environments. This has inevitably put people in a particular consuming, and paradoxically controlling as well as dependency relationship with the environment. Consequently, now it is becoming apparent that current levels of consumption in Western and aspiring Western societies are unsustainable, governments are concerned to reduce consumption levels through changing the behaviours of consumers. Western societies are characterised by the need for companies to position their products on the market and generate a need and demand for increased consumption, and in many cases at any cost, in order to ensure escalating profits and continued national economic growth. This has led us to suggest a reformulation of sustainable development to include relations of production and consumption and the political relations that produce environmentally damaging ways of producing and consuming. Such a reformulation inevitably poses critical questions for environmental psychology and challenges environmental psychology to address these complex relationships in such a way as to see the relationships between individuals, society and the environment as mutually constitutive and reciprocal.

This kind of thinking should not be problematic for environmental psychologists. Within a transactionalist perspective we recognise that the individual and the external world are linked in complex and mutual ways and can only be treated together as one phenomenon - their inter-relationship and reciprocity is the unit of analysis (Stokols and Shumaker, 1981; Altman and Rogoff, 1987). Within a transactionalist perspective neither the individual, the social group nor the setting can be defined without reference to the others. Action and change in one will influence the others. The environment embodies the psychologies and the social relations of those who live in it. It confers meaning, promotes identity, locates the person socially, culturally and economically. Bonnes and Secchiaroli (1995) suggest that transactionalism has two primary features: the continuous exchange and reciprocity between the individual and the environment, and the primarily active and intentional role of the individual to the environment. We would revise this by suggesting that environments also constitute individuals without their conscious involvement in it. Therefore, instead of looking at individuals, society and the environment as if they existed independently of each other, there is a need to take a relational view of individuals and society and their relationship to the environment, and in so doing look precisely at the reciprocity between people and environment and the ways in which they mutually reproduce the material conditions for their existence.

The emphasis in a transformative environmental psychology should shift from individuals as only consumers, from 'user perceptions and evaluations' and 'consumer behaviours' to the relations of production and consumption and the social relations within which (un)sustainable ways of living and the environment are produced and reproduced. A new research agenda in environmental psychology would incorporate a more comprehensive view of individuals as workers and consumers, and invest more energy in understanding the ways in which individuals and their "values, norms and behaviours" concerning (un)sustainability are constituted by the ways in which they work. Reformulating people-environment relationships in these terms inevitably requires environmental psychologists to consider their work from the point of view of the empowerment of individuals. 
As soon as we start to raise these issues in the context of relations of production and consumption and political relations, then key variables such as interests, control, power and influence enter the research agenda. Whose interests are being served in the planning, design, management and use of our cities? What power and influence do users have?

Perhaps more than any other area of psychology, environmental psychology has sought and received research funding from government departments and agencies as much as research councils, more so as local, national and international governments have seen how environmental psychology can assist and inform the formulation and implementation of government policies. Governments are concerned to find out what are the most effective means of persuading the public to consume more sustainably, but in a way that does not impact upon economic growth. This is assumed to be on behalf of the public and for the public's benefit. But the State is not some kind of neutral agency sitting above the people and acting as an arbiter between the competing claims of interest groups, but an interest group like any other, with its own ideology and competing for power and influence and representing the interests of particular groups (Lively, 1978). It is a relation (Saunders, 1979), for example, between those in government and the dominant class/gender/ethnic/spatial interests. So when environmental psychologists undertake research for government in order to contribute to sustainable development policy, this is not necessarily undertaken on a social, political or economically neutral landscape. Therefore it is important to ask, whose interests, unwittingly and even unwillingly, do environmental psychologists serve? Saving the planet may be the altruistic intention, but even altruistic intentions can have uneven and undesirable impacts. The recently highly publicised case of the use of biofuels is an example of how a technological solution to reduce greenhouse gases has highly damaging and discriminatory environmental and social costs. The production of palm oil, sugar and corn to feed cars rather than people is not only leading competition for scarce agricultural land and a rise in food prices but the destruction of the rain forests, reduced biodiversity and soil destruction.

Psychologists are required to operate under sets of ethical principles and codes of conduct. The British Psychological Society provides a detailed code (BPS, 2006) which is prefaced by a general statement: "In all circumstances, investigators must consider the ethical implications and psychological consequences for the participants in their research. The essential principle is that the investigation should be considered from the standpoint of all participants; foreseeable threats to their psychological well-being, health, values or dignity should be eliminated. Investigators should recognise that, in our multi-cultural and multiethnic society and where investigations involve individuals of different ages, gender and social background, the investigators may not have sufficient knowledge of the implications of any investigation for the participants. It should be borne in mind that the best judge of whether an investigation will cause offence may be members of the population from which the participants in the research are to be drawn.

This raises many pertinent issues for a socially conscious and just environmental psychology. Do we always consider the implications of our research from the standpoint of all participants? The strict notion of participants in research is a limited one - should it not be "...the investigation should be considered from the standpoint of all those affected." Do we really think through who all the potential participants are (i.e., those who might be affected)? For example, if we conduct research among a British or Swedish population into attitudes towards biofuels, do we interview farmers in Borneo for their attitudes too so that a more balanced evaluation of the desirability, implications and benefits of such a development can 
be evaluated? To what extent do we truly interrogate and explore the potential foreseeable threats to the "psychological well-being, health, values or dignity....... individuals of different ages, gender and social background".

It is, of course, exciting to contribute to policymaking, not least of which because it makes us feel valued and convinces us that we are making a contribution to society - but whose society and whose interests in society? The job of the environmental psychology researcher is to enhance our understanding of people-environment relationships. We would question whether it is to provide advice to governments and industry on how to make 'the responsible consumer'. In this paper we suggest that if the problems of climate change are to be addressed, then the focus of our efforts should not be what is it to be a sustainable consumer, but predominantly, what is it to be a sustainable producer and how can citizens exert more democratic influence on production and consumption processes?

We believe that the argumentation that we present here moves environmental psychology some way forward from its traditional approach to examining people-environment relationships. It does not necessarily seek to replace that approach but it does suggest an alternative perspective which raises different types of questions and looks in a different way at the relationships among people, and between them and the environment in the broadest sense. This difference might be characterised as a change in focus from the influence of and the adaptability to the built and natural environment to the social production of the environment. 


\section{References}

Altman, I. \& Rogoff, B. (1987). World views in Psychology: Trait, Interactional, Organismic and Transactional Perspectives. In D. Stokols \& I. Altman (Eds) Handbook of Environmental Psychology, Volume 1. Florida: Krieger Publishing Company, pp 1-40.

Basso, P. (2003). Modern times, ancient hours, London \& New York: Verso

Bauman, Z. (1992). Intimations of postmodernity. London, New York : Routledge

BBC (2000). Men behind the fuel protests, http://news.bbc.co.uk/1/hi/uk/1003552.stm Site Accessed: April 2007

Becker, F. and Steele, F. (1995). Workplace by design: mapping the high-performance workscape. San Francisco: Jossey-Bass.

Bem, D. J. (1972). Self-perception theory, Advances in Experimental Social Psychology, 6, 2 $-62$.

Bonaiuto, M. Breakwell, G. M. and Cano, I (1996). Identity processes and environmental threat: the effects of nationalism and local identity upon perception of beach pollution. Journal of Community and Applied Social Psychology, 6: 157 -175.

Bonnes, M. \& Bonaiuto, M. (2002). Environmental psychology: From spatial-physical environment to sustainable development. In R. Bechtel \& A. Churchman (Eds.),

Handbook of environmental psychology (pp. 28-54). New York: Wiley.

Bonnes, M. \& Secchiaroli, G. (1995). Environmental psychology. a psycho-social introduction. London: Sage.

Bourdieu, P. (1984). Distinction. A social critique of the judgement of taste. Translation: R Nice. London: Routledge.

BPS (2006). Ethical Principles for conducting research with human participants - general principles, Leicester: British Psychological Society, 2006 http://www.bps.org.uk/thesociety/ethics-rules-charter-code-of-conduct/code-of-conduct/ethical-principles-forconducting-research-with-human-participants.cfm\#principles

Carson, R. (1962). Silent Spring, New York: Houghton Mifflin Company.

Castree, N. and Braun, B. (1998). 'The construction of nature and the nature of construction: analytical and political tools for building survivable futures' in B. Braun and N. Castree (eds.) Remaking reality: nature at the millenium, London: Routledge, pp 3-42.

Castree, N. (2005). Nature. London and New York: Routledge

Clayton, S. and Brook, A (2005). Can psychology help save the world? A model for conservation psychology, Analyses of Social Issues and Public Policy, Vol. 5, No. 1, pp. 87-102

Dobson, A. (1996). Environmental sustainabilities: an analysis and a typology, Environmental Politics, 5, 3, pp. 401-428.

Dunlap, R.E., Gallup, G.H. and Gallup, A.M. (1993). Of global concern: Results of the Health of the Planet Survey, Environment, 35, 9, 7-15, 33-40.

Gardner, G.T., \& Stern, P.C. (2002). Environmental problems and human behavior $\left(2^{\text {nd }}\right.$ edition). Boston, MA: Pearson Custom Publishing.

Gärling, T \& Hartig, T. (2000). Environmental psychology's relationship to the environmental (design) professions, Newsletter of the International Association of Applied Psychology, 12, 1, pp 30-32.

Gereluk, W., Royer, L. (2001): Sustainable Development of the Global Economy: A Trade Union Perspective. Geneva: International Labour Office. 
Graumann, C. (1983). On multiple identities, International Social Science Journal, 35, 309321.

Hardin, G., (1968). The Tragedy of the Commons, Science, Vol. 162, No. 3859 (13

December, 1968), pp. 1243-1248

Harris, J. (2007). The burning issue, The Guardian Weekend, 14 April 2007, pp 28-32.

Huckle, J. \& Sterling, S. (1999). Education for Sustainability: an invitation to join a debate. Published paper, available from http://john.huckle.org.uk/publications downloads.jsp. (Accessed 22 November, 20078)

Kasser, T. (2002). The High Price of Materialism, Cambridge, MA: MIT Press.

Lefèbvre, H. (1991). The Production of Space. Oxford: Blackwell Publishers.

Lawrence, R. and Després, C. (2004). 'Futures of Transdisciplinarity', Futures, 36, 4, 397 405

Lélé, S. M. (1991). Sustainable development: a critical review. World Development 19 (6): 607-621.

Lively, J. (1978). 'Pluralism and consensus', in P. Birnbaum, J. Lively and G. Parry (eds.) Democracy, Consensus and Social Contract, London: Sage.

Maffesoli, M. (1996). The Time of Tribes. Seven Oaks: Sage.

McCoy, J. (2002). 'Work environments' in R.. B. Bechtel and A. Churchman (eds.)

Handbook of environmental psychology, New York: Wiley, 443 - 460

McCoy, J., \& Evans, G.W. (2005). The physical work environment. In J. Barling, K. Kelloway, \& M. Frome (Eds.), Handbook of work stress (pp. 219-246). Los Angeles: Sage.

McDowell, L. (1997). Capital Culture. Gender at Work in the City. Oxford: Blackwell.

Meadows, D H., Meadows L., Randers, J. and Behrens, W. (1972). The Limits to Growth: A Report for the Club of Rome's Project on the Predicament of Mankind. New York: Universe Books.

McKenzie-Mohr, D. (2000). New ways to promote pro-environmental behavior: promoting sustainable behavior: an introduction to community-based social marketing, Journal of Social Issues, Volume 56, 3, 543.

Plant, C and Plant, J, (1991). Green business: hope or hoax. Philadelphia: New Society Publishers.

Pol, E. (2002). The theoretical background of the city-identity-sustainability network. Environment and Behavior, Volume 34, Number 1, pp. 8-25

Proshansky, H. M., Ittelson, W H. \& Rivlin, L. G. (1970). Environmental psychology: man and his physical setting. New York: Holt, Rinehart \& Winston.

Saegert, S. (2004) Book Review: Handbook of Environmental Psychology. In: Journal of Environmental Psychology. Volume 24, Issue 2, June 2004, Pages 259-263

Saunders, P. (1979). Community power, urban managerialism and the 'Local State', Paper presented at the Centre for Environmental Studies Conference 'Urban Change and Conflict', University of Nottingham, 5 - 8 January.

Steg, L. (2005). Car use: lust and must. Instrumental, symbolic and affective motives for car use, Transportation Research Part A: Policy and Practice, Volume 39, Number 2-3.

Stokols, D. \& Shumaker, S.A. (1981). People in places: A transactional view of settings. In: J. Harvey (ed.) Cognition, Social Behaviour and the Environment. NJ. Erlbaum.

Sundstrom, E. (1986). Work places: the psychology of the physical environment in offices and factories. New York: Cambridge University Press.

Turner, J.C., Hogg, M.A., Oakes, P.J., Reicher, S.D. and Wetherell, M.S. (1987). Rediscovering the Social Group: A Self-Categorization Theory. Cambridge, MA: Blackwell.

United Nations Conference on the Human Environment (1972) Stockholm, June 5-16, 1972. 
Uzzell, D. (2000a). 'Environmental Psychology and the Environmental (Design) Professions - a Comment on Gärling and Hartig' Newsletter of the International Association of Applied Psychology, 12, 1, pp 32-34.

Uzzell, D. (2000b). The psycho-spatial dimension to global environmental problems, Journal of Environmental Psychology, 20, 4, pp 307- 318.

Uzzell, D., Pol, E and Badenas, D. (2002). Place identification, social cohesion and environmental sustainability, Environment and Behavior, 34, 1, 26-53.

Vlek, C., \& Steg, L. (2007). Human behavior and environmental sustainability: Problems, driving forces and research topics. Journal of Social Issues, 63 (1), 1-19. (see whole issue) 